\title{
A Grading System For The Prediction Of Unilateral Chronic Subdural Hematoma Recurrence After Initial Single Burr Hole Evacuation
}

Risk Management and Healthcare Policy

Jun Shen $\mathbb{D}^{1-3, *}$
Wenqiang $\mathrm{Xin}^{2,3}$
Qifeng $\mathrm{Li}^{2,3, *}$
Yalong $\mathrm{Gao}^{2,3, *}$
Jianning Zhang

'Department of Neurosurgery, Yijishan Hospital of Wannan Medical College, Wuhu City, Anhui 24I00I, People's Republic of China; ${ }^{2}$ Department of Neurosurgery, Tianjin Medical University General Hospital, Tianjin 300052. People's Republic of China; ${ }^{3}$ Key Laboratory of Post-Trauma Neuro-Repair and Regeneration in Central Nervous System, Ministry of Education, Tianjin, 300052, People's Republic of China

*These authors contributed equally to this work
Correspondence: Jianning Zhang Department of Neurosurgery, Tianjin Medical University General Hospital, Tianjin 300052, People's Republic of China

Tel/fax +8622608I4359

Email jianningzhang@hotmail.com
Background and purpose: Previous studies have identified many risk factors related to the recurrence of chronic subdural hematomas (CSDHs). Among these factors, there may be deviations in measuring the midline shift, preoperative hematoma volume (PreHV), postoperative hematoma residual volume, and postoperative pneumocephalus in bilateral CSDHs. The aims of this study were to eliminate the impact of complicated situations on parameter measurement and to identify actual predictors for CSDH recurrence, and finally, to develop a grading system to predict unilateral CSDH (uCSDH) recurrence.

Patients and methods: A total of 342 patients with uCSDH were identified. Predictors of $\mathrm{uCSDH}$ recurrence were obtained from univariable and multivariable logistic regression models. A prognostic grading system was developed based on the results of multivariable logistic regression and receiver operating characteristic (ROC) analyses. All patients were scored according to the grading system, and differences in the recurrence rate were reanalyzed according to the scores.

Results: Age, antiplatelet or anticoagulant use, midline shift, severe brain atrophy, drainage volume, and the ratio of the postoperative pneumocephalus volume (PostPV) to the postoperative hematoma cavity volume (PostHCV) were identified as independent risk factors for predicting the recurrence of $\mathrm{uCSDH}$. The cut-off values of age, drainage volume, midline shift, and the ratio of the PostPV to the PostHCV were 67 years, $101 \mathrm{~mL}, 11.2 \mathrm{~mm}$, and $31.61 \%$, respectively. The recurrence rates were $1.7 \%, 12.4 \%, 19.4 \%, 53.3 \%$, and $58.3 \%$ for scores of $0-1,2,3,4$, and 5-6, respectively, which significantly increased as the score increased $(P<0.001)$.

Conclusion: The prognostic grading system for $\mathrm{uCSDH}$ on the basis of multivariable logistic regression and ROC analyses is applicable and reliable.

Keywords: brain atrophy, chronic subdural hematoma, Glasgow Coma Scale, Glasgow Outcome Scale, grading system, recurrence rate

\section{Introduction}

Chronic subdural hematoma $(\mathrm{CSDH})$ is one of the most common intracranial hematomas and is predominantly encountered in elderly people after head trauma. The annual incidence of CSDH is 16.3 per 100,000 individuals and up to 58.1 per 100,000 in patients over 65 years of age, ${ }^{1}$ while the incidence of CSDH continues to increase as the population ages. ${ }^{2}$ Although CSDH is recognized as benign and has a favorable prognosis after surgical evacuation according to a previous opinion, 
the recurrence rate has been reported to be as high as $5 \%$ to $30 \%{ }^{2}$ with a mortality rate of $9.1 \%$ in the general population and up to $16.7 \%$ in the elderly. ${ }^{3,4}$

Previous studies have identified many risk factors related to recurrence of $\mathrm{CSDH}$, including age, ${ }^{5}$ sex, ${ }^{5}$ bilateral hematomas, ${ }^{6}$ antiplatelet or anticoagulant use, ${ }^{7,8}$ brain atrophy, ${ }^{9}$ computer tomography (CT) density, ${ }^{9,10}$ midline shift, ${ }^{6}$ preoperative hematoma volume (PreHV), ${ }^{9,10}$ postoperative hematoma residual volume, ${ }^{10}$ and postoperative pneumocephalus. ${ }^{11}$ Among these factors, there may be deviations in measuring the midline shift, PreHV, postoperative hematoma residual volume, and postoperative pneumocephalus, because there are some situations that have not been documented, such as the $\mathrm{CSDH}$ being unilateral or bilateral; if bilateral CSDHs (bCSDHs) exist, whether the surgical procedure was performed on a single side or on both sides; and if a single-side operation was performed on bCSDHs, whether contralateral hematoma progression occurred after surgery.

In the present study, we excluded bCSDHs to eliminate the impact of complicated situations on parameter measurement and to identify actual predictors for $\mathrm{CSDH}$ recurrence. Finally, we developed a grading system to predict unilateral $\mathrm{CSDH}(\mathrm{uCSDH})$ recurrence, because most CSDHs are unilateral (bCSDH accounts for approximately $20 \%{ }^{12}$ ).

\section{Materials And Methods}

\section{Patients And Methods}

\section{Exclusion Criteria}

We retrospectively analyzed patients with $\mathrm{CSDH}$ who were admitted to the Department of Neurosurgery, Yijishan Hospital of Wanan Medical College, China, between October 2012 and November 2018. The exclusion criteria included the following: (1) bCSDHs or contralateral subdural effusion; (2) age $<18$ years; (3) CSDH due to cerebrovascular disease; (4) patients with arachnoid cysts; (5) underwent an intracranial operation 6 months prior to admission; (6) acute epidural hematoma or acute subdural hematoma after surgery; and (7) patients with missing data. A total of 342 patients with uCSDH were identified in this study (Figure 1).

\section{Surgical Procedure}

All patients in our study received a uniform surgical procedure. After local or general anesthesia, a single burr hole craniotomy was performed at the thickest layer of the hematoma, and a silicone catheter was placed into the hematoma cavity and rinsed with warm saline until the liquid that flowed out became clear. A closedsystem drainage was connected to the catheter and placed at the patient's head level. The drainage system was removed within 3 days after surgery.

\section{CT Scan And Imaging Analysis}

Head CT scans at admission and within three days after surgery were performed in all patients. Brain atrophy was classified as follows: (1) no or mild atrophy, (2) moderate atrophy, and (3) severe atrophy. Hematomas were classified into five types according to their density (Figure 2), as follows: (1) homogeneous (homogeneous hypodense, homogeneous isodense and homogeneous hyperdense), (2) separated or gradation, (3) laminar, (4) trabecular, and (5) mixed. Hematoma densities of types (1) to (4) have been described in a previous study, ${ }^{10}$ whereas the mixed density was defined as having two or more of the above mentioned types of CT density appearing on one layer or on a different layer in one patient. The PreHV, postoperative hematoma volume (PostHV), and postoperative pneumocephalus volume (PostPV) were calculated as follows: $\sum$ [layer thickness $\times$ area of each layer]. The area of the layer was measured with Image $J$ software. The postoperative hematoma cavity volume (PostHCV) was calculated as PostHV+PostPV. The rate of hematoma clearance was calculated as follows: (PreHV-PostHV)/ PreHV. The extent of hematoma cavity reduction was calculated as follows: (PreHV-PostHCV)/PreHV.

\section{Parameters Included In The Statistical Analysis}

The following clinical and radiological parameters were included in the statistical analysis: age, sex, history of head trauma, use of antiplatelet or anticoagulant drugs, hypertension, diabetes mellitus, presenting Glasgow Coma Scale (GCS) score, Glasgow Outcome Scale (GOS) score, drainage volume, midline shift, hematoma side, hematoma density, brain atrophy, PreHV, PostHV, PostPV, PostHCV, the rate of hematoma clearance, the extent of hematoma cavity reduction, the ratio of the PostPV to the PreHV, the ratio of the PostPV to the PostHCV, and the ratio of the PostHV to the PreHV. All the parameters were measured by 1 neuroradiologist and 2 neurosurgeons who were blinded to the study.

\section{Follow-Up And Definition Of CSDH Recurrence}

All patients were followed up at the outpatient department for more than three months after discharge. During follow-up, patients who had new onset or worsening of 


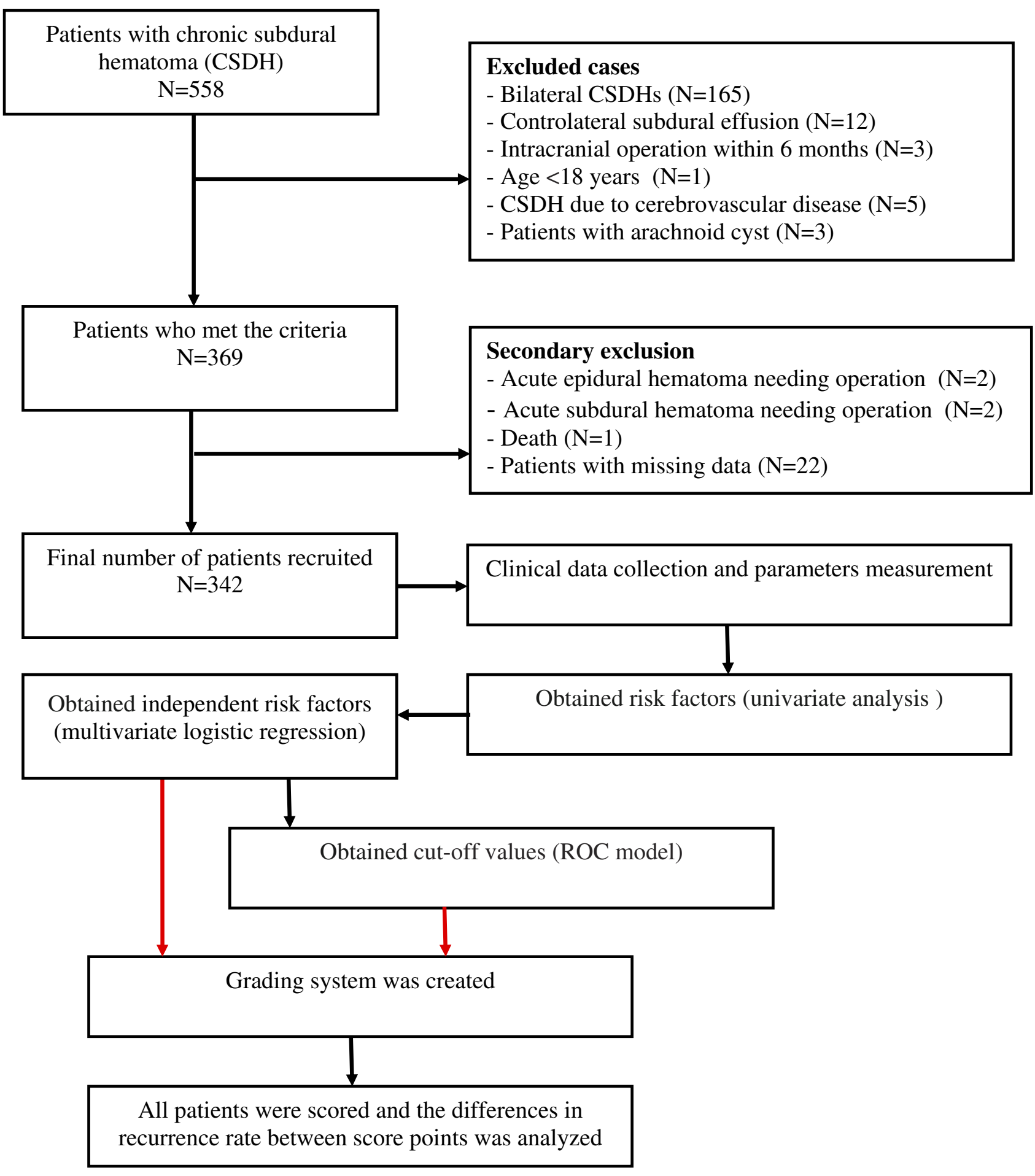

Figure I The experimental flow chart and exclusion criteria of this study. Notes: Red arrows indicate the ultimate purpose of this study.

neurological symptoms underwent a CT scan immediately, and an increase in the hematoma volume in the CT scans that needed another surgery was defined as CSDH recurrence.

\section{Statistical Analyses}

Data are presented as the numbers of patients (percentages) and as the means \pm standard deviations (SDs) for categorical and continuous variables, respectively. A 

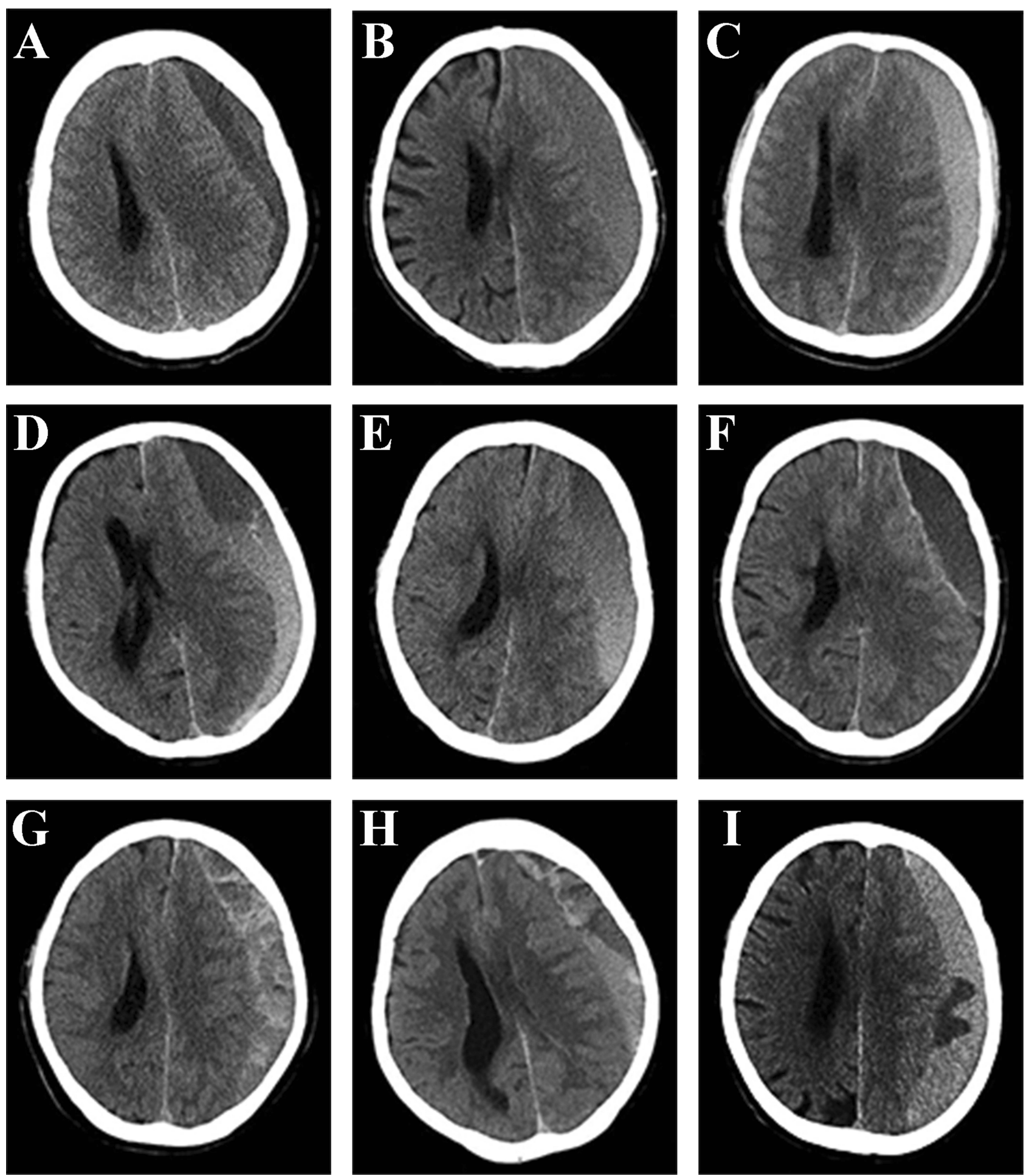

Figure 2 The classification of CSDH according to the hematoma density on CT performance. This classification is based on previous research. ${ }^{10}$ (A) Homogenous hypodense. (B) Homogenous isodense. (C) Homogenous hyperdense. (D) Separated type, the two components of the hematoma are clearly separated. (E) Gradation type, the density of the hematoma gradually changes from hyperdense to hypodense. (F) Laminar type, a linear hyperdense located in the inner membrane of the hematoma. (G) Trabecular type, the hematoma was separated by several high-density septa. $(\mathbf{H}$ and $\mathbf{I})$ Mixed density, two or more types of CT density appear on one layer or on the different layer in one patient.

univariable analysis was performed with Student's $t$-test or the $\chi^{2}$ test where appropriate. Variables with a $P$-value $<0.05$ in the univariable analysis were included in the multivariable logistic regression model. A receiver operating characteristic (ROC) curve was created from independent risk factors obtained from the multivariable logistic 
regression analysis. The area under the curve (AUC), 95\% confidence interval (CI) and cut-off value of the continuous variables were recorded. A grading system was created on the basis of the independent risk factors from the multivariable logistic regression analysis and cut-off values from the ROC model. All statistical analyses were conducted with SPSS (version 22.0, IBM Corp.), $P<0.05$ was considered statistically significant. The ROC model was analyzed with MedCalc statistical software (version 14.8, Ostend, Belgium).

\section{Results}

\section{Patient Characteristics}

A total of 342 patients with uCSDH were identified as meeting the criteria. There were 62 women $(18.1 \%)$ and 280 men $(81.9 \%)$ in this study, and the mean age at diagnosis was 68.13 years (range from 21 to 88 years). Recurrence was identified in 52 patients, and the recurrence rate was $15.2 \%(17.7 \%$ in women and $14.6 \%$ in men).

\section{Univariable Analysis}

The univariable analysis of factors related to recurrence is shown in Table 1. The mean age of the recurrence group was $71.67 \pm 10.09$ years, which was significantly older than that of the no recurrence group $(67.49 \pm 12.05$ years; $P=0.019$ ). Patients with antiplatelet or anticoagulant use and severe brain atrophy had a higher recurrence rate ( $P=0.043$ and $P<0.001$, respectively). The GOS score at discharge was significantly lower in the recurrence group than in the no recurrence group $(P=0.009)$. The midline shift, drainage volume, PreHV, and PostPV were significantly higher in the recurrence group than in the no recurrence group. To determine whether the PostPV is related to the PreHV and PostHCV, the ratios of the PostPV to the PreHV and PostHCV were analyzed, and the results revealed that the ratios of the PostPV to both the PreHV and PostHCV were significantly higher in the recurrence group than in the no recurrence group.

\section{Multivariable Logistic Regression Analysis}

The results of the multivariable logistic regression analysis are shown in Table 2. Age, antiplatelet or anticoagulant use, midline shift, severe brain atrophy, drainage volume, and the ratio of the PostPV to the PostHCV were identified as independent risk factors for predicting the recurrence of $\mathrm{uCSDH}$.
Table I Univariable Analysis Of Clinical And Radiological Parameters Related To Recurrence Of Unilateral CSDH

\begin{tabular}{|c|c|c|c|}
\hline \multirow[t]{2}{*}{ Factors } & \multicolumn{2}{|c|}{ Number Of Patients (\%) } & \multirow[t]{2}{*}{$P$ value } \\
\hline & Recurrence & No Recurrence & \\
\hline Total & $52(15.2 \%)$ & $290(84.8 \%)$ & \\
\hline $\begin{array}{l}\text { Sex } \\
\qquad \text { Male } \\
\text { Female }\end{array}$ & $\begin{array}{l}4 \mathrm{I}(14.6 \%) \\
\text { II (I7.7\%) }\end{array}$ & $\begin{array}{l}239(85.4 \%) \\
51(82.3 \%)\end{array}$ & 0.539 \\
\hline Age (years) & $71.67 \pm 10.09$ & $67.49 \pm 12.05$ & 0.019 \\
\hline $\begin{array}{l}\text { History of trauma } \\
\text { Yes } \\
\text { No }\end{array}$ & $\begin{array}{l}26(14.9 \%) \\
26(15.6 \% \square\end{array}$ & $\begin{array}{l}149 \text { (85.1\%) } \\
|4|(84.4 \%)\end{array}$ & 0.855 \\
\hline $\begin{array}{l}\text { Hypertension } \\
\text { Yes } \\
\text { No }\end{array}$ & $\begin{array}{l}15(13.3 \%) \\
37(16.2 \%)\end{array}$ & $\begin{array}{l}98(86.7 \%) \\
192(83.8 \%)\end{array}$ & 0.485 \\
\hline $\begin{array}{l}\text { Diabetes Mellitus } \\
\text { Yes } \\
\text { No }\end{array}$ & $\begin{array}{l}6(20.7 \%) \\
46(14.7 \%)\end{array}$ & $\begin{array}{l}23(79.3 \%) \\
267(85.3 \%)\end{array}$ & 0.555 \\
\hline $\begin{array}{l}\text { Antiplatelet or } \\
\text { anticoagulant use } \\
\text { Yes } \\
\text { No }\end{array}$ & $\begin{array}{l}6(35.3 \%) \\
46(14.2 \%)\end{array}$ & $\begin{array}{l}\text { II (64.7\%) } \\
279(85.8 \%)\end{array}$ & 0.043 \\
\hline $\begin{array}{l}\text { Anesthesia } \\
\text { Local } \\
\text { General }\end{array}$ & $\begin{array}{l}18(13.8 \%) \\
34(16.0 \%)\end{array}$ & $\begin{array}{l}\text { II (86.2\%) } \\
\text { I } 78 \text { (84.0\%) }\end{array}$ & 0.584 \\
\hline GCS at admission & $14.60 \pm 0.87$ & $14.52 \pm 1.03$ & 0.636 \\
\hline GOS at discharge & $4.48 \pm 0.73$ & $4.77 \pm 0.50$ & 0.009 \\
\hline $\begin{array}{l}\text { Hematoma side } \\
\text { Left } \\
\text { Right }\end{array}$ & $\begin{array}{l}22(I 5.2 \%) \\
30(I 5.2 \%)\end{array}$ & $\begin{array}{l}\text { I23 (84.8\%) } \\
\text { I67 (84.8\%) }\end{array}$ & 0.989 \\
\hline Midline shift & $11.62 \pm 3.65$ & $10.38 \pm 4.04$ & 0.041 \\
\hline $\begin{array}{l}\text { Brain atrophy } \\
\text { No or mild } \\
\text { Moderate } \\
\text { Severe }\end{array}$ & $\begin{array}{l}4(4.1 \%) \\
11(7.7 \%) \\
47(42.0 \%)\end{array}$ & $\begin{array}{l}94(95.9 \%) \\
131(92.3 \%) \\
65(58.0 \%)\end{array}$ & $<0.001$ \\
\hline $\begin{array}{l}\text { Hematoma density } \\
\text { Homogeneous } \\
\text { Homogeneous }\end{array}$ & $\begin{array}{l}30(15.9 \%) \\
3(5.9 \%)\end{array}$ & $\begin{array}{l}159(84.1 \%) \\
48(94.1 \%)\end{array}$ & 0.119 \\
\hline $\begin{array}{l}\text { hypodense } \\
\text { Homogeneous }\end{array}$ & $15(16.0 \%)$ & 79 (84.0\%) & \\
\hline isodense & & & \\
\hline $\begin{array}{l}\text { Homogeneous } \\
\text { hyperdense }\end{array}$ & $12(27.3 \%)$ & $32(72.7 \%)$ & \\
\hline Laminar & $2(7.7 \%)$ & $24(92.3 \%)$ & \\
\hline Separated & 8 (21.1\%) & $30(78.9 \%)$ & \\
\hline Trabecular & $10(20.0 \%)$ & $40(80.0 \%)$ & \\
\hline Mixed & $2(5.0 \%)$ & 38 (95.0\%) & \\
\hline
\end{tabular}

(Continued) 
Table I (Continued).

\begin{tabular}{|l|l|l|l|}
\hline \multirow{2}{*}{ Factors } & \multicolumn{2}{|l|}{ Number Of Patients (\%) } & \multirow{2}{*}{ P value } \\
\cline { 2 - 3 } & Recurrence & No Recurrence & \\
\hline Drainage volume $(\mathrm{mL})$ & $183.75 \pm 204.93$ & $101.39 \pm 119.86$ & $\mathbf{0 . 0 0 7}$ \\
\hline PreHV $\left(\mathrm{cm}^{3}\right)$ & $183.17 \pm 50.05$ & $154.42 \pm 54.03$ & $<0.001$ \\
\hline PostHV $\left(\mathrm{cm}^{3}\right)$ & $74.09 \pm 38.12$ & $75.63 \pm 123.5$ & 0.929 \\
\hline PostPV $\left(\mathrm{cm}^{3}\right)$ & $42.51 \pm 33.79$ & $18.96 \pm 24.39$ & \\
\hline PostHCV $\left(\mathrm{cm}^{3}\right)$ & $116.61 \pm 37.46$ & $94.59 \pm 133.85$ & 0.24 \\
\hline $\begin{array}{l}\text { Rate of hematoma } \\
\text { clearance }\end{array}$ & $0.592 \pm 0.183$ & $0.477 \pm 1.166$ & 0.478 \\
\hline $\begin{array}{l}\text { Hematoma cavity } \\
\text { volume reduction }\end{array}$ & $0.3514 \pm 0.176$ & $0.355 \pm 1.249$ & 0.984 \\
\hline PostPV/PreHV & $0.241 \pm 0.187$ & $0.122 \pm 0.160$ & $<0.001$ \\
\hline PostPV/PostHCV & $0.364 \pm 0.242$ & $0.203 \pm 0.189$ & $<0.001$ \\
\hline PostHV/PreHV & $0.408 \pm 0.183$ & $0.523 \pm 1.166$ & 0.478 \\
\hline
\end{tabular}

Notes: Significant $P$ values are in bold type.

Abbreviations: GCS, Glasgow Coma Scale; GOS, Glasgow Outcome Scale; PostHCV, postoperative hematoma cavity volume; PostHV, postoperative hematoma volume; PostPV, postoperative pneumocephalus volume; PreHV, preoperative hematoma volume.

Table 2 Multivariable Logistic Regression Analysis Of Factors Related To Recurrence Of Unilateral CSDH

\begin{tabular}{|l|l|l|l|}
\hline Factor & $\begin{array}{l}\text { Adjusted } \\
\text { OR }\end{array}$ & $\mathbf{9 5 \%} \mathbf{C I}$ & P value \\
\hline Age & 1.053 & $1.007-1.100$ & $\mathbf{0 . 0 2 3}$ \\
Antiplatelet or & 4.802 & $1.139-20.248$ & $\mathbf{0 . 0 3 3}$ \\
anticoagulant use & & & \\
GOS at discharge & 3.84 & $0.873-16.897$ & 0.075 \\
Midline shift & 0.879 & $0.798-0.981$ & $\mathbf{0 . 0 2 1}$ \\
Brain atrophy & 11.74 & $4.427-31.131$ & $<0.001$ \\
Drainage volume $(\mathrm{mL})$ & 0.998 & $0.996-1.000$ & $\mathbf{0 . 0 4 2}$ \\
PreHV (cm $\left.{ }^{3}\right)$ & 0.999 & $0.989-1.010$ & 0.895 \\
PostPV (cm $\left.{ }^{3}\right)$ & 1.013 & $0.972-1.056$ & 0.532 \\
PostPV/PreHV & 0.109 & $0.000-36.898$ & 0.456 \\
PostPV/PostHCV & 0.031 & $0.002-0.416$ & $\mathbf{0 . 0 0 9}$ \\
\hline
\end{tabular}

Notes: Significant $\mathrm{P}$ values are in bold type.

Abbreviations: $\mathrm{Cl}$, confidence interval; GOS, Glasgow Outcome Scale; OR, Odds Ratio; PostHCV, postoperative hematoma cavity volume; PosthV, postoperative hematoma volume; PostPV, postoperative pneumocephalus volume; PreHV, preoperative hematoma volume.

\section{ROC Curve Analysis}

The independent risk factors obtained from the multivariable logistic regression model were entered into the ROC model. Figure 3 presents the ROC curves of the six independent risk factors. The AUC, $95 \% \mathrm{CI}$ and cut-off values

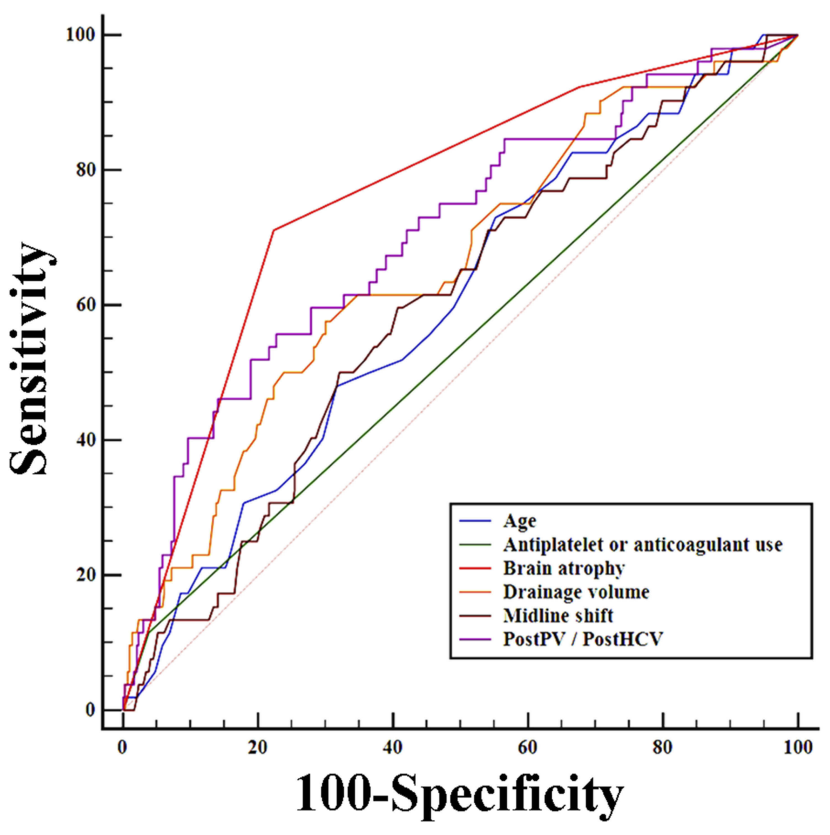

Figure 3 ROC model of the six independent risk factors obtained from the multivariate logistic regression analysis.

Abbreviations: PostPV, postoperative pneumocephalus volume; PostHCV, postoperative hematoma cavity volume.

of the continuous variables are presented in Table 3. The cut-off values of age, the ratio of the PostPV to the PostHCV, drainage volume, and midline shift were 67 years, $31.61 \%, 101 \mathrm{~mL}$, and $11.2 \mathrm{~mm}$, respectively.

\section{Development Of A Prognostic Grading System}

Based on the results of multivariable logistic regression and ROC curve analyses, a prognostic grading system was developed and is shown in Table 4. To make this grading system simple for clinical reference, the PostPV/PostHCV ratio, drainage volume, and midline shift were adjusted to $33.33 \%(1 / 3), 100 \mathrm{~mL}$ and $11 \mathrm{~mm}$, respectively. We assume that this scoring system is applicable, and all patients were then scored, and differences in the recurrence rate were analyzed according to the scores. The recurrence rates were $1.7 \%, 12.4 \%, 19.4 \%, 53.3 \%$, and $58.3 \%$ for scores of $0-1,2,3,4$, and 5-6, respectively, which significantly increased as the score increased $(P<0$. 001) (Table 5).

\section{Discussion}

$\mathrm{CSDH}$ is usually encountered in elderly people in neurosurgical practice as the population ages. Regardless of 
Table 3 Characteristics In The ROC Curves Of The Six Independent Risk Factors

\begin{tabular}{|l|l|l|l|l|}
\hline Variables & AUC & SE & $95 \%$ Cl & $\begin{array}{l}\text { Cut-Off } \\
\text { Value }\end{array}$ \\
\hline Antiplatelet or & 0.539 & 0.023 & $0.484-0.592$ & NA \\
anticoagulant use & & & & \\
Brain atrophy & 0.761 & 0.034 & $0.712-0.805$ & NA \\
Age & 0.6 & 0.042 & $0.545-0.652$ & $>67$ years \\
PostPV/PostHCV & 0.702 & 0.041 & $0.651-0.750$ & $>31.61 \%$ \\
Drainage volume $(\mathrm{mL})$ & 0.656 & 0.042 & $0.603-0.706$ & $>101 \mathrm{~mL}$ \\
Midline shift & 0.595 & 0.042 & $0.541-0.648$ & $>11.2 \mathrm{~mm}$ \\
\hline
\end{tabular}

Abbreviations: AUC, area under the curve; $\mathrm{Cl}$, confidence interval; NA, not available; PostHCV, Postoperative hematoma cavity volume; PostPV, postoperative pneumocephalus volume; SE, standard error.

Table 4 The Prognostic Grading System For Unilateral CSDH Recurrence

\begin{tabular}{|c|c|}
\hline $\begin{array}{l}\text { Components Of The Prognostic Grading } \\
\text { System }\end{array}$ & $\begin{array}{l}\text { Score } \\
\text { Points }\end{array}$ \\
\hline $\begin{array}{l}\text { Antiplatelet or anticoagulant use } \\
\text { Yes } \\
\text { No }\end{array}$ & $\begin{array}{l}1 \\
0\end{array}$ \\
\hline $\begin{array}{l}\text { Severe brain atrophy } \\
\text { Yes } \\
\text { No }\end{array}$ & $\begin{array}{l}1 \\
0\end{array}$ \\
\hline $\begin{array}{l}\text { Age } \\
>67 \text { years } \\
\leq 67 \text { years }\end{array}$ & $\begin{array}{l}1 \\
0\end{array}$ \\
\hline $\begin{array}{l}\text { PostPV/PostHCV } \\
>33.33 \%(1 / 3) \\
\leq 33.33 \%(1 / 3)\end{array}$ & $\begin{array}{l}1 \\
0\end{array}$ \\
\hline $\begin{array}{l}\text { Drainage volume }(\mathrm{mL}) \\
>100 \mathrm{~mL} \\
\leq 100 \mathrm{~mL}\end{array}$ & $\begin{array}{l}1 \\
0\end{array}$ \\
\hline $\begin{array}{l}\text { Midline shift } \\
>11 \mathrm{~mm} \\
\leq 11 \mathrm{~mm}\end{array}$ & $\begin{array}{l}1 \\
0\end{array}$ \\
\hline Total score & 6 \\
\hline
\end{tabular}

Table 5 The Recurrence Rate Of Patients With Different Scores

\begin{tabular}{|l|l|l|l|l|}
\hline Scores & Recurrence & $\begin{array}{l}\text { No } \\
\text { Recurrence }\end{array}$ & $\begin{array}{l}\text { Recurrence } \\
\text { Rate }\end{array}$ & $\begin{array}{l}\boldsymbol{P} \\
\text { value }\end{array}$ \\
\hline $0-1$ & 2 & 118 & $1.70 \%$ & $<0.001$ \\
2 & 14 & 99 & $12.40 \%$ & \\
3 & 13 & 54 & $19.40 \%$ & \\
4 & 16 & 14 & $53.30 \%$ & \\
$5-6$ & 7 & 5 & $58.30 \%$ & \\
\hline
\end{tabular}

Abbreviations: PostHCV, postoperative hematoma cavity volume; PostPV, postoperative pneumocephalus volume. which surgical strategy may be selected, the recurrence rate of CSDH is still high and causes permanent neurological damage or even death in some patients. ${ }^{2,12}$ Therefore, the identification of risk factors associated with CSDH recurrence is meaningful for postoperative management and therapeutic trials; for example, Atorvastatin was recently proven to reduce CSDH by 29 $\mathrm{mL}$ after 8 weeks of consecutive administration, ${ }^{13}$ and Dexamethasone was demonstrated to reduce the recurrence rate and avoid a reoperation for recurrent $\mathrm{CSDH}^{14,15}$

Previous studies have shown that CT density is associated with CSDH recurrence. Stanišic M, et al reported that the incidence, hyperdense, laminar, and separated types of CSDH were risk factors associated with recurrence. ${ }^{10}$ Jack A et al showed that separated CSDH was an independent risk factor for predicting the recurrence of CSDH. ${ }^{9}$ However, we and others did not find a positive correlation between $\mathrm{CT}$ density and the recurrence of CSDH. ${ }^{16,17}$ In addition, we analyzed the CT images of all patients and found that the previous types of CT density did not include all patients. Two or more types of CT density may appear on one layer or on different layers in one patient. Therefore, we defined a mixed type for these patients.

Severe brain atrophy, antiplatelet or anticoagulant use, and age were identified as independent risk factors for CSDH recurrence, and these results were consistent with those from previous studies. ${ }^{5,7,9}$ Due to the mass effect of the hematoma, the measurement of brain atrophy on the initial CT scan is subjective and not precise. ${ }^{10}$ Therefore, the degree of brain atrophy was identified on postoperative and follow-up CT images. The drainage volume was significantly higher in the recurrence group than in the no recurrence group. Excessive drainage may cause a large amount of cerebrospinal fluid (CSF) to enter the hematoma cavity, while CSF leakage into the subdural space could be involved in the pathogenesis and recurrence of CSDH and subdural hygroma. ${ }^{12,18}$ This theory can also explain why the recurrence rate in patients with severe brain atrophy was significantly higher (i.e., because the subdural space of patients with severe brain atrophy is wider, it easily accumulates CSF). Although sex and GOS scores were considered to be associated with the recurrence of $\mathrm{CSDH},{ }^{5,19}$ they were not identified as independent risk factors in the present study.

Contralateral hematoma progression after the unilateral evacuation of bCSDH is usually encountered in 
neurosurgical practice. ${ }^{20-23}$ Some patients even experienced an increase in the volume of the contralateral hematoma within one day after unilateral surgery. ${ }^{23}$ One explanation for this phenomenon is that an increase in the volume of the contralateral hematoma is due to a reduction in intracranial pressure after a unilateral operation (i.e., the larger the ipsilateral hematoma is, the higher the pressure relief on the untreated side, followed by contralateral hematoma expansion). ${ }^{22}$ This suggests existing bias in some parameter measurements of bCSDHs, such as the midline shift, PreHV, PostHV, and PostPV. We eliminated the bCSDHs in this study to reduce bias and to determine the actual parameters associated with $\mathrm{CSDH}$ recurrence.

Although the XYZ/2 method has been demonstrated to be reliable for CSDH by Sucu et $\mathrm{al}^{24}$ and others, ${ }^{2,23}$ it is not suitable for the measurement of the PostHV and PostPV because the postoperative hematoma and air are often irregular and mixed together. To quantitatively analyze the PostHV and PostPV, we measured the area of the postoperative hematoma and pneumocephalus at each layer, added the area of all layers, and multiplied by the layer thickness, thus obtaining the volume. The PreHV and PostPV have been demonstrated to be independent risk factors for the recurrence of $\mathrm{CSDH},{ }^{9,10}$ and in the present study, both were identified as risk factors but not independent risk factors; only the ratio of the PostPV to the PostHCV was revealed as an independent risk factor. To the best of our knowledge, this was the first time that bCSDHs were excluded to eliminate the impact of complicated situations on parameter measurement and that the PostPV and PostHV were analyzed together with the PreHV and PostHCV.

There are only two grading systems available in published literature. ${ }^{9,10}$ Jack A et al $^{9}$ described a prognostic grading system for CSDH recurrence based on a patient's age (with a cut-off value of 80 years), the PreHV (with a cut-off value of $160 \mathrm{~mL}$ ), and the presence of hematoma septation. Stanišić $\mathrm{M}$ et al ${ }^{10}$ developed a prognostic grading system based on the CT imaging appearance (isodense, hyperdense, laminar and separated types of hematoma), PreHV (cut-off value of $130 \mathrm{~mL}$ ), and PostHCV (with a cut-off value of 80 and $200 \mathrm{~mL}$ ). However, the PostHV and PostPV were not measured in the two studies, and the midline shift was ignored by Stanišic $\mathrm{M}$ et al.

In the present study, we developed a new grading system for $\mathrm{uCSDH}$ recurrence based on multivariable logistic regression and ROC curve analyses. Among the six components of this grading system, antiplatelet or anticoagulant use, severe brain atrophy, age, drainage volume, and midline shift were identified conveniently. Only the ratio of the PostPV to the PostHCV needs to be carefully measured. The cut-off value of age in the present study was 67 years, which is far younger than that previously reported ( 80 years). ${ }^{9,10}$ The recurrence rate of $\mathrm{CSDH}$ was significantly increased as the score increased, revealing that the prognostic grading system is applicable and reliable.

There are some inevitable limitations to this study. First, the prognostic grading system applies only to $\mathrm{UCSDH}$ recurrence, and the risk factors for bCSDH recurrence should be further investigated. Next, for homogeneous isodense $\mathrm{CSDH}$, the boundary between the hematoma and the normal brain tissue is not clear. Although magnetic resonance imaging (MRI) was performed in most homogeneous isodense CSDH patients, some patients who needed emergency surgery did not undergo an MRI examination. We tried our best to adjust the threshold of the hematoma and combine the upper and lower layers to measure the area of the hematoma; however, there may still be bias. Finally, this was a single-center study, and the number of $\mathrm{uCSDH}$ patients was small; therefore, a multicenter, large sample size study is needed to confirm our results and the reliability of the prognostic grading system of uCSDH recurrence.

\section{Conclusion}

This study demonstrated that age, antiplatelet or anticoagulant use, midline shift, severe brain atrophy, drainage volume, and the ratio of the PostPV to the PostHCV were independent risk factors for predicting the recurrence of uCSDH. The cutoff values of age, drainage volume, midline shift, and the ratio of the PostPV to the PostHCV were 67 years, $101 \mathrm{~mL}$, $11.2 \mathrm{~mm}$, and $31.61 \%$, respectively. The prognostic grading system for uCSDH on the basis of multivariable logistic regression and ROC curve analyses is applicable and reliable.

\section{Abbreviations}

AUC, area under the curve; bCSDHs, bilateral chronic subdural hematomas; CI, confidence interval; $\mathrm{CSDH}$, chronic subdural hematoma; GCS, Glasgow Coma Scale; GOS, Glasgow Outcome Scale; PostHCV, postoperative hematoma cavity volume; PostHV, postoperative hematoma volume; PostPV, postoperative pneumocephalus volume; PreHV, preoperative hematoma volume; ROC, receiver operating characteristic; SD, standard deviation; SE, standard error; $\mathrm{uCSDH}$, unilateral chronic subdural hematoma. 


\section{Ethics Statement}

We obtained ethical approval to carry out this study from the Institutional Review Board (IRB) of Yijishan Hospital of Wannan Medical College, Wuhu, China. All patients or their relatives provided written informed consent for this research, which was carried out in compliance with the Helsinki Declaration. All individual information was strictly kept confidential and anonymous in the manuscript.

\section{Acknowledgment}

This study was supported by a grant from the Collegiate Major Natural Science Research Projects (Grant No. KJ2017A267, Anhui Provincial Department of Education, China).

\section{Author Contributions}

Jun Shen and Jianning Zhang designed this research. Jun Shen obtained the follow-up data, carried out the statistical analysis, and wrote the manuscript. Wenqiang Xin, Qifeng Li and Yalong Gao measured the radiological parameters. Qifeng Li and Yalong Gao prepared the figures and tables. All authors contributed towards data analysis, drafting and critically revising the paper, gave final approval of the version to be published, and agreed to be accountable for all aspects of the work.

\section{Disclosure}

The authors report no conflicts of interest in this work.

\section{References}

1. Kudo H, Kuwamura K, Izawa I, et al. Chronic subdural hematoma in elderly people: present status on Awaji Island and epidemiological prospect. Neurol Med Chir (Tokyo). 1992;32:207-209. doi:10.2176/ nmc.32.207

2. Santarius T, Kirkpatrick PJ, Ganesan D, et al. Use of drains versus no drains after burr-hole evacuation of chronic subdural haematoma: a randomised controlled trial. Lancet. 2009;374:1067-1073. doi:10.1016/S0140-6736(09)61115-6

3. Szczygielski J, Gund SM, Schwerdtfeger K, et al. Factors affecting outcome in treatment of chronic subdural hematoma in ICU patients: impact of anticoagulation. World Neurosurg. 2016;92:426-433. doi:10.1016/j.wneu.2016.05.049

4. Miranda LB, Braxton E, Hobbs J, et al. Chronic subdural hematoma in the elderly: not a benign disease. J Neurosurg. 2011;114:72-76. doi:10.3171/2010.8.JNS10298

5. Motoie R, Karashima S, Otsuji R, et al. Recurrence in 787 patients with chronic subdural hematoma: retrospective cohort investigation of associated factors including direct oral anticoagulant use. World Neurosurg. 2018;18:e87-e91. doi:10.1016/j.wneu.2018.06.124

6. Schwarz F, Loos F, Dünisch P, et al. Risk factors for reoperation after initial burr hole trephination in chronic subdural hematomas. Clin Neurol Neurosurg. 2015;138:66-71. doi:10.1016/j.clineuro.2015.08.002
7. Nathan S, Goodarzi Z, Jette N, et al. Anticoagulant and antiplatelet use in seniors with chronic subdural hematoma: systematic review. Neurology. 2017;88:1889-1893. doi:10.1212/WNL.0000000000003918

8. Rust T, Kiemer N, Erasmus A. Chronic subdural haematomas and anticoagulation or anti-thrombotic therapy. $J$ Clin Neurosci. 2006;13:823-827. doi:10.1016/j.jocn.2004.12.013

9. Jack A, O'Kelly C, McDougall C, et al. Predicting recurrence after chronic subdural haematoma drainage. Can J Neurol Sci. 2015;42 (1):34-39. doi:10.1017/cjn.2014.122

10. Stanišić M, Pripp AH. A reliable grading system for prediction of chronic subdural hematoma recurrence requiring reoperation after initial burr-hole surgery. Neurosurgery. 2017;81:752-760. doi:10. 1093/neuros/nyx090

11. You CG, Zheng XS. Postoperative pneumocephalus increases the recurrence rate of chronic subdural hematoma. Clin Neurol Neurosurg. 2018;166:56-60. doi:10.1016/j.clineuro.2018.01.029

12. Kolias AG, Chari A, Santarius T, et al. Chronic subdural haematoma: modern management and emerging therapies. Nat Rev Neurol. 2014;10:570-578. doi:10.1038/nrneurol.2014.163

13. Jiang R, Zhao S, Wang R, et al. Safety and efficacy of atorvastatin for chronic subdural hematoma in chinese patients: a randomized clinicaltrial. JAMA Neurol. 2018;75:1338-1346. doi:10.1001/ jamaneurol.2018.2030

14. Berghauser Pont LM, Dammers R, Schouten JW, et al. Clinical factors associated with outcome in chronic subdural hematoma: a retrospective cohort study of patients on preoperative corticosteroid therapy. Neurosurgery. 2012;70:873-880. doi:10.1227/NEU.0b013e31823672ad

15. Zhang Y, Chen S, Xiao Y, et al. Effects of dexamethasone in the treatment of recurrent chronic subdural hematoma. World Neurosurg. 2017;105:115-121. doi:10.1016/j.wneu.2017.05.135

16. Tsai TH, Lieu AS, Hwang SL, et al. A comparative study of the patients with bilateral or unilateral chronic subdural hematoma: precipitating factors and postoperative outcomes. $J$ Trauma. 2010;68:571-575. doi:10.1097/TA.0b013e3181a5f31c

17. Mori K, Maeda M. Surgical treatment of chronic subdural hematoma in 500 consecutive cases: clinical characteristics, surgical outcome, complications, and recurrence rate. Neurol Med Chir (Tokyo). 2001;41:371-381. doi:10.2176/nmc.41.371

18. Kristof RA, Grimm JM, Stoffel-Wagner B. Cerebrospinal fluid leakage into the subdural space: possible influence on the pathogenesis and recurrence frequency of chronic subdural hematoma and subdural hygroma. J Neurosurg. 2008;108:275-280. doi:10.3171/JNS/2008/ $108 / 2 / 0275$

19. Abouzari M, Rashidi A, Zandi-Toghani M, et al. Chronic subdural hematoma outcome prediction using logistic regression and an artificial neural network. Neurosurg Rev. 2009;32:479-484. doi:10.1007/ s10143-009-0215-3

20. Motiei-Langroudi R, Thomas AJ, Ascanio L, et al. Factors predicting the need for surgery of the opposite side after unilateral evacuation of bilateral chronic subdural hematomas. Neurosurgery. 2018;85(2)E1-E8.

21. Fujitani S, Ishikawa O, Miura K, et al. Factors predicting contralateral hematoma growth after unilateral drainage of bilateral chronic subdural hematoma. J Neurosurg. 2017;126:755-759. doi:10.3171/ 2016.1.JNS152655

22. Scheichel F, Popadic B, Ungersboeck K, et al. Contralateral progression after unilateral evacuation of bilateral chronic subdural hematomas: the volume relation ratio as prognostic factor? J Neurosurg. 2018;1:1-8.

23. Takahashi S, Yamauchi T, Yamamura T, et al. Proposal of treatment strategies for bilateral chronic subdural hematoma based on laterality of treated hematoma. Asian J Neurosurg. 2018;13:1134-1139. doi:10.4103/ajns.AJNS_124_18

24. Sucu HK, Gokmen M, Gelal F. The value of XYZ/2 technique compared with computer-assisted volumetric analysis to estimate the volume of chronic subdural hematoma. Stroke. 2005;36:9981000. doi:10.1161/01.STR.0000162714.46038.0f 


\section{Publish your work in this journal}

Risk Management and Healthcare Policy is an international, peerreviewed, open access journal focusing on all aspects of public health, policy, and preventative measures to promote good health and improve morbidity and mortality in the population. The journal welcomes submitted papers covering original research, basic science, clinical \& epidemiological studies, reviews and evaluations, guidelines, expert opinion and commentary, case reports and extended reports. The manuscript management system is completely online and includes a very quick and fair peer-review system, which is all easy to use. Visit http://www.dovepress.com/testimonials.php to read real quotes from published authors. 